\title{
An Outcome Analysis of Community Rehabilitation Programs
}

\author{
Nicole Fraedrich ${ }^{1}$ a \\ 1 Utah State Office of Rehabilitation \\ Keywords: employment outcomes, community rehabilitation providers, vocational rehabilitation \\ https://doi.org/10.52017/001c.28198
}

\section{Rehabilitation Counselors and Educators Journal}

Vol. 10, Issue 2, 2021

\begin{abstract}
State Vocational Rehabilitation (VR) programs frequently partner with community rehabilitation programs (CRPs) to provide key employment support to individuals with significant disabilities. However, the employment outcomes for many individuals have consisted of a lengthy period of time to placement, low wages, and limited hours. The Utah State Office of Rehabilitation (USOR) sought to learn whether recent agency CRP policy changes had a positive influence on client employment outcomes and use results to inform further internal evaluation efforts.
\end{abstract}

\section{Background and Purpose}

State Vocational Rehabilitation (VR) agencies frequently contract with community rehabilitation programs (CRPs) to deliver a variety of employment services to individuals with disabilities who require support to obtain and maintain employment (Lukyanova et al., 2015). It is estimated that there are nearly 12,000 CRPs nationally, and the majority provide services to individuals with intellectual disabilities (50\%) and those with mental illnesses (19\%), followed by physical disabilities (9\%) and sensory impairments (4\%) (Domin \& Butterworth, 2012). In terms of competitive integrated employment, prior research indicated that CRPs successfully placed approximately $25 \%$ of clients in part-time jobs and $7 \%$ in full-time jobs with wages averaging $\$ 8.25$ per hour, with $68 \%$ of clients remaining unemployed despite the provision of services (Suarez-Balcazar et al., 2013). Suarez-Balcazar and colleagues (2013) also noted that it took CRPs an average of seven months to help individuals obtain employment but could take up to eighteen months in some cases.

VR agencies have limited resources to provide all services internally. Due to limited resources, it is critical to collaborate with external providers when clients need intensive services or support, such as job readiness training, placement services, and on-the-job support services. The Utah State Office of Rehabilitation (USOR) spends approximately one-third of its annual budget on intensive employment-related services to individuals with significant disabilities provided by CRPs. Following an internal qualitative study with the assistance of a national Technical Assistance Center, USOR significantly updated and implemented their CRP-related policies effective January 1, 2020. The policy updates were intended to (a) improve job placement rates, (b) decrease the time to placement, and (c) define employment quality indicators, such as client wages and number of hours worked. As an incentive to encourage higher qual- ity employment outcomes, the new USOR policy opted to pay CRPs an additional $\$ 500$ for job placements where the client works more than 30 hours per week, earns over \$14/ hour, lives or works in a rural county, and is placed within 60 days of referral. USOR also pays an additional $\$ 500$ for clients placed in a STEM occupation, and with employerpaid health benefits. All conditions must be met to receive each of these milestone payments. Those indicators are not analyzed in this study. Surveys and focus groups informed the policy revisions, however, extensive data analysis did not occur prior to implementing the change in policy. Therefore, the state agency sought to better understand how the policy change impacted employment outcomes at the client level, specifically for those with significant disabilities.

The purpose of the study was to investigate the relationships between client demographic factors and the quality of the employment outcomes among those who received services from CRPs. The demographic factors included gender, age, disability type, and geographic location (i.e., rural vs. urban) of placements. Quality of employment was evaluated using hourly wage, hours worked per week, and the number of days to placement.

\section{Methods}

This evaluation looked at outcomes from two and a half years of CRP placements prior to implementing significant policy change regarding how USOR compensated CRPs. The target sample included clients that began receiving job placement services through CRPs from April 1, 2017 to December 31, 2019 and exited USOR with a successful employment outcome. The sample $(n=899)$ exited USOR between September 28, 2017 and April 22, 2021. The demographic factors included gender, age, disability type, and geographic location (i.e., rural vs. urban) of placements. Frequency and 
Table 1. VR Client Wage, Hours Worked, and Average Days to Placement by Age

\begin{tabular}{ccccc}
\hline Age at application & Number & Average hourly wage & Average hours worked & Average days to placement \\
\hline Under 18 & 191 & $\$ 9.44$ & 20.93 & 142.83 \\
$19-21$ & 201 & $\$ 9.56$ & 19.60 & 172.10 \\
$22-40$ & 340 & $\$ 9.91$ & 20.57 & 148.35 \\
$41-64$ & 162 & $\$ 10.41$ & 22.18 & 128.32 \\
Over 65 & 5 & $\$ 11.63$ & 22.20 & 160.40 \\
\hline
\end{tabular}

Table 2. VR Client Wage, Hours Worked, and Average Days to Placement by Geographic Location

\begin{tabular}{cccc}
\hline Service area & Average hourly wage & Average weekly hours & Average days to placement \\
\hline Rural & $\$ 8.99$ & 19.12 & 174.13 \\
Urban & $\$ 9.95$ & 20.96 & 115 \\
& & 784.28 \\
\hline
\end{tabular}

means were then calculated and used as a baseline for quality indicators. The quality indicators were based on High Quality Indicators (HQI) outlined in USOR's CRP fee schedule. Hourly wage, hours worked per week, and days to placement were used as baseline employment quality indicators. Days to placement were calculated with the issue date for the job development authorization (when a CRP begins job search with a client) and the invoice date for the placement authorization.

\section{Results}

The results of this study are divided into two basic categories: (a) overall placement quality and (b) demographic trends in placement outcomes. Overall, hourly wages at exit showed $55.2 \%$ of clients making less than $\$ 10 /$ hour, whereas only $6.2 \%$ were making over $\$ 14$ /hour. Additionally, $18.1 \%$ of clients were working over 30 hours per week, with $42.9 \%$ of clients working between 11-20 hours per week. In terms of the average number of days between referral and job placement, the process took more than 120 days for $41.1 \%$ of clients served and less than 60 days for $29.7 \%$. In relation to age at application, it was discovered that wages increased with age, whereas the number of hours worked per week did not increase until over the age of 40 . Those in the 19-22-year-old age group experienced the longest time to placement, with an average of 172.1 days. See Table 1.

\section{Gender}

When analyzing gender, quicker placement occurred for males at an average of 139.34 days, whereas females averaged 164.73 days. Male clients also had a slightly higher hourly wage (\$9.92) and hours worked (21.36 hours) compared with outcomes of female clients, with wages of $\$ 9.67$ per work and working an average of 19.63 hours per week.

\section{Urban Versus Rural Geographic Location}

Clients in urban areas earned an average of nearly one dollar more per hour (\$9.95) and worked nearly two more hours per week (20.96) than those residing in rural areas. The average number of days to placement for those in urban areas (145.28) was 28.85 days shorter than for those in rural areas (174.13). See Table 2.

\section{Race}

The majority of the sample was White (91.7\%) with an hourly wage of $\$ 9.81$. Individuals identifying with more than one race and Native Hawaiian/Pacific Islander reported higher wages than other groups. It is important to note these are low numbers due to the demographics of Utah, representing just 25 of the 899 clients analyzed. Native Americans averaged an hourly wage of \$10.67 and those with multiple races averaged $\$ 10.47$ per hour. See Table 3 .

\section{Disability}

In terms of disability type, the percentage of individuals served in each category through USOR was consistent with national estimates. In USOR, individuals with sensory impairments had slightly higher wages ( $\$ 10.37$ per hour) but experienced a longer time to placement (191.13 days). Individuals with physical and mental disabilities had similar hourly wages, but those with physical disabilities experienced the shortest placement time of 131.11 days. The average number of hours worked was comparable across all three groups. See Table 4.

\section{Recommendations and Implications for Practice}

The results of this study will be used to further analyze changes made to recent USOR CRP policies, with a specific focus at incentivizing quality employment outcomes by CRP providers. Initially the design of this study intended to focus on the 60 days to placement incentive, as implemented with the January 2020 policy changes. Due to the challenges presented by COVID-19, the data generated in 2020 was not indicative of typical business practices of USOR or the CRPs. Further analysis of the baseline data will allow us to inform 
Table 3. VR Client Wage, Hours Worked, and Average Days to Placement by Race

\begin{tabular}{|c|c|c|c|c|}
\hline Race & $\begin{array}{l}\text { Average hourly } \\
\text { wage }\end{array}$ & $\begin{array}{l}\text { Average weekly } \\
\text { hours }\end{array}$ & $\begin{array}{l}\text { Average days to } \\
\text { placement }\end{array}$ & $\mathrm{n}$ \\
\hline American Indian or Alaskan Native & $\$ 9.74$ & 21.73 & 205.29 & 15 \\
\hline Asian & $\$ 9.65$ & 22.42 & 148.17 & 12 \\
\hline Black or African American & $\$ 10.09$ & 22.23 & 95.71 & 22 \\
\hline Does not wish to self-identify & $\$ 9.50$ & 20.00 & 273.00 & 1 \\
\hline Multiple & $\$ 10.47$ & 21.55 & 190.91 & 22 \\
\hline $\begin{array}{l}\text { Native Hawaiian or Other Pacific } \\
\text { Islander }\end{array}$ & $\$ 10.67$ & 22.00 & 206.33 & 3 \\
\hline White & $\$ 9.81$ & 20.62 & 147.83 & 824 \\
\hline Non-White & $\$ 10.07$ & 21.92 & 161.01 & 75 \\
\hline
\end{tabular}

Table 4. VR Client Wage, Hours Worked, and Average Days to Placement by Disability Type

\begin{tabular}{lcccc}
\hline \multicolumn{1}{c}{ Disability type } & Average hourly wage & Average weekly hours & Average days to placement & $\mathrm{n}$ \\
\hline Sensory & $\$ 10.37$ & 21.89 & 191.13 & $46(5 \%)$ \\
Physical & $\$ 9.90$ & 21.57 & 131.11 & $77(9 \%)$ \\
Mental (includes cognitive) & $\$ 9.79$ & 20.57 & 148.15 & 776 (86\%) \\
\hline
\end{tabular}

on policy as well as evaluate the effectiveness of the HighQuality Indicator incentives. Based on findings from this study, the following observations and recommendations are offered:

- Identify the dates for excluding data or, alternatively, analyze it separately to account for anomalies caused by the COVID-19 pandemic.

- Clearly define how to pull data in the case management system to support clean calculation, without needing to further review case notes and attachments for clarification.

- Identify specific demographics in advance, as necessary, to adjust for policy and factors.

- Further analysis may include agency cost information across client demographic groups and associated outcomes to inform policy and service delivery.

- In addition to completing qualitative analyses, con- duct a thorough quantitative baseline data analysis prior to making any changes in policy.

\section{Author Note}

The contents of this paper were developed under a cooperative agreement with the U.S. Department of Education, Technical Assistance Center for Vocational Rehabilitation Agency Program Evaluation and Quality Assurance (PEQA-TAC) (Grant Award Number: H263B150004). However, the contents and views expressed in this publication do not necessarily represent the positions or policies of the U.S. Department of Education, and you should not assume endorsement by the Federal government. 


\section{References}

Domin, D., \& Butterworth, J. (2012). The 2010-2011 national survey of community rehabilitation providers report 1: Overview of services, trends and provider characteristics. In Research to Practice Brief, Issue No. 52. University of Massachusetts Boston, Institute for Community Inclusion.
Lukyanova, V., Suarez-Balcazar, Y., Balcazar, F., \& Oberoi, A. (2015). A case file review of employment outcomes from community rehabilitation providers. Journal of Vocational Rehabilitation, 43(1), 33-40. http s://doi.org/10.3233/IVR-150752

Suarez-Balcazar, Y., Lukyanova, V. V., Balcazar, F., Ali, A., Morton, D., \& Alvarado, F. (2013). Employment outcomes of community rehabilitation providers. Journal of Rehabilitation, 79(1), 11-18. 